\title{
Analysis of the engineering process of reforming dead catalysts for the extraction of platinum group metals
}

\author{
N. M. Vostrikova ${ }^{1, a}$, E. D. Kravtsova ${ }^{1}$, Y. V.Vostrikova ${ }^{2}$ \\ 'Siberian Federal University, Krasnoyarsk, Russia \\ ${ }^{2}$ National University of Oil and Gas «Gubkin University» Moscow, Russia \\ avnatali59@mail.ru
}

Keywords: platinum-rhenium catalyst, catalytic reforming, regeneration, sweet roasting, carbonaceous deposits

\begin{abstract}
The analysis of the engineering process of reforming dead catalysts for the extraction of platinum group metals has been carried out. Fully-dead catalyst, having passed several cycles of regeneration and entitled to utilization, has the considerable carbonaceous deposits both on external and internal surface. Their content averages $5.0 \%$ of the mass of the catalyst.

The research objective consisted in selection of the sweet roasting modes promoting the fullest removal of the dense carbonaceous deposits from the surface of the dead platinum-rhenium catalysts.

The kinetics research of carbonaceous removal deposits from the surface of the catalyst was carried out in a pipe-still heater; oxygen content, duration and temperature of sweet roasting being varied. The maximum temperature during the research reached $950^{\circ} \mathrm{C}$, the maximum duration of isothermical holding didn't exceed 6 hours. The extent of carbonaceous deposits removal was calculated by changing sample weight.

The kinetic curves were approximated by high-order polynomials, which made it possible to obtain a diagram illustrating the degree of organic deposits removal depending on the temperature and firing time.

It is shown that in the environment enriched to 30-35 vol. \% oxygen, the engineering process of catalysts for regeneration is possible to be carried out at $650{ }^{\circ} \mathrm{C}$, with holding for 2 hours at the specified temperature. The alternative of sweet roasting is the air blowing of dead catalysts at temperature of $800{ }^{\circ} \mathrm{C}$ within one hour. Both modes guarantee the complete removal of the dense carbonaceous deposits from the surface of the dead catalyst.
\end{abstract}

\section{Introduction}

Substantial progress at deep oil refining was reached due to the large-scale implementation of catalytic reforming. In the course of hydrocatalytic reforming of oil raw materials such products as reformate (a high-octane product), individual aromatic hydrocarbons or light isoparaffin hydrocarbons and also hydrogen are obtained.

Commercially the process of catalytic reforming has been used since 1940 [1]. The main active component of catalysts is always platinum which coat the carrier material - aluminum oxide. The progress reached during commercialization of catalytic reforming process consisting in increase in selectivity and a yield of the desired product is connected first of all with the development of new advanced, multimetallic catalysts, which structure except platinum also contains other valuable components - rhenium, iridium, germanium, etc. [2].

Formally the catalyst is not consumed in the course of reaction and does not participate in the stoichiometric equation of reactions, however, in the process of operating its activity gradually decreases, consequently, a base product yield degree gets worse when the catalyst is used. Appearing on its surface carbonaceous deposits blocking the active centers of the catalyst can be a reason. [3]. 
In this respect it is necessary to carry out regeneration of the catalyst periodically. However, after the first regeneration catalysts restore the activity only for $90 \%$. Besides, there occurs a partial destruction of the catalyst form. As a result of three - six regenerative cycles the general activity of the catalyst decreases almost to $50 \%$. It has been found by the authors [4] that the decrease of catalytic operation efficiency of the platinum-rhenium catalyst during the process of reforming installation at Achinsk Oil Refinery, is shown after four cycles of regeneration and is followed by the substantial change of its structure and structural properties.

Thus, after several cycles of regeneration, restoration of activity to the level close to the one of fresh catalysts is impossible. Then the catalyst is brought out of oil processing and goes for utilization; at the same time expensive metals are required to be transferred to a form of individual water-soluble salts. However, considerable deposits of organic impurities on the surface of the catalysts arriving on utilization block hydrochemical processes. The organic deposits which are from 5 to $20 \%$ of the mass of the carrier material, consist generally of the multicondensed aromatic compounds with high molecular weight, with a low ratio of $\mathrm{H} / \mathrm{C}$ and high temperature of their oxidation $\left(500-600^{\circ} \mathrm{C}\right)[5]$.

According to the data [6], the main reason of difficult extraction Pt and Pd from dead catalysts of petrochemical processes is their high coking. At the same time, if a dead catalyst is prewashed with organic solvent, this will lead to the increasing of leaching efficiency from 25 to $52 \%$.

For regeneration of catalysts the technologies based on oxidizing removal of carbonaceous deposits [7] are used; the removal occurs whether directly in the hydrotreater or by means of specialized facilities. We are offered a wide range of techniques to clean an aluminium oxide basis of catalysts from organic deposits. The following one is the most widely applied, it is hightemperature oxidation at temperature of $500-800{ }^{\circ} \mathrm{C}$ in a current of dry air [8]. There are more difficult ways, e.g., plasma-chemical act [9] can be directed both to pretreatment of the initial catalyst to increase its catalytic activity, and to regeneration of the dead catalysts. In papers [10, 11] it is shown that at low temperatures of ozone oxidation (up to $125^{\circ} \mathrm{C}$ in comparison with hightemperature burning out of coke in the presence of oxygen at $450{ }^{\circ} \mathrm{C}$ ) of coked-up catalysts, processes of migration and agglomeration of active components ( $\mathrm{Pt}, \mathrm{Re}$ ) are excluded, i.e. the parent structure of the metallic phase remains the same. The efficiency has been proved by the authors [12] and the plant [13] for regeneration of the coked-up catalysts by extraction with participation of supercritical fluids has been patented.

The above mentioned methods of the engineering process of dead petroleum chemistry catalysts for metallurgical processing are considered to be rather effective, but too expensive, or the process demands special equipment.

Sweet roasting providing removals of organic impurities in the form of gaseous products carbon oxides, water vapors, in some cases oxides of sulfur is the simplest and the most effective method at the first stage of utilization. Despite the similar mechanism, kinetics of oxidation is significantly various for different types of catalysts, which is connected both with properties of the deleted carbonaceous deposits, and with properties of catalysts.

The research objective consisted in selection of the sweet roasting modes promoting the fullest removal of the dense carbonaceous deposits from the surface of the dead platinum-rhenium catalysts. It will give an opportunity to carry out the engineering process of dead catalysts of hydrocarbon processing containing precious metals for the metallurgical processing, the major purpose of which is quantitative extraction of precious metals.

\section{Experimental}

Subject of research was platinum-rhenium reforming catalyst REF-23. In the initial state this type of catalyst looks like extruded articles from alumina, with a diameter of $1.2-1.6 \mathrm{~mm}$, about 5 $\mathrm{mm}$ long, with pour grains density of $0.62-0.66 \mathrm{~g} / \mathrm{cm} 3$, and a specific surface of $200-250 \mathrm{sq} . \mathrm{m} / \mathrm{g}$.

Fully-dead catalyst, having passed several cycles of regeneration and entitled to utilization, has the considerable carbonaceous deposits both on external and internal surface (fig. 1). 


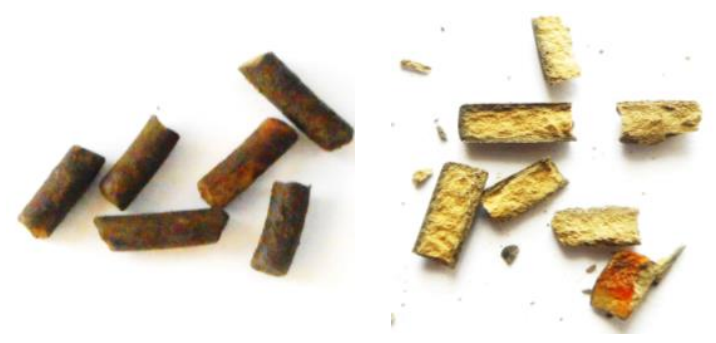

Fig.1. Appearance and inner part of the reforming catalyst after several cycles of regeneration

The kinetics research of carbonaceous removal deposits from the surface of the catalyst was carried out in a pipe-still heater; oxygen content, duration and temperature of sweet roasting being varied. The maximum temperature during the research reached $950^{\circ} \mathrm{C}$, the maximum duration of isothermical holding didn't exceed 6 hours.

\section{Results and discussion}

Pilot experiments proved that at the long isothermal holding at $950^{\circ} \mathrm{C}$, the mass of three samples changed respectively to $2,647,2,629,2.624 \mathrm{~g}$, that in terms of $50 \mathrm{~g}$ of the test charge makes $5.27 \pm 0.04 \%$. Thus it was accepted that the change of sample weight for $5.27 \%$ corresponds to the complete removal of carbonaceous deposits from the surface of reforming catalyst subject to utilization.

The isothermal holding at $110{ }^{\circ} \mathrm{C}$ leads to the change of sample weight from $50 \mathrm{~g}$ of the catalyst not more than to $0.02 \mathrm{~g}$, that corresponds to samples humidity of $0.04 \%$. This data value is at the level of inaccuracy of measurements, and it can be neglected.

In fig. 2 kinetic curve removals of carbonaceous deposits from the surface of the catalyst when roasting in the air environment at variation of temperature from $500{ }^{\circ} \mathrm{C}$ to $800{ }^{\circ} \mathrm{C}$ are presented.

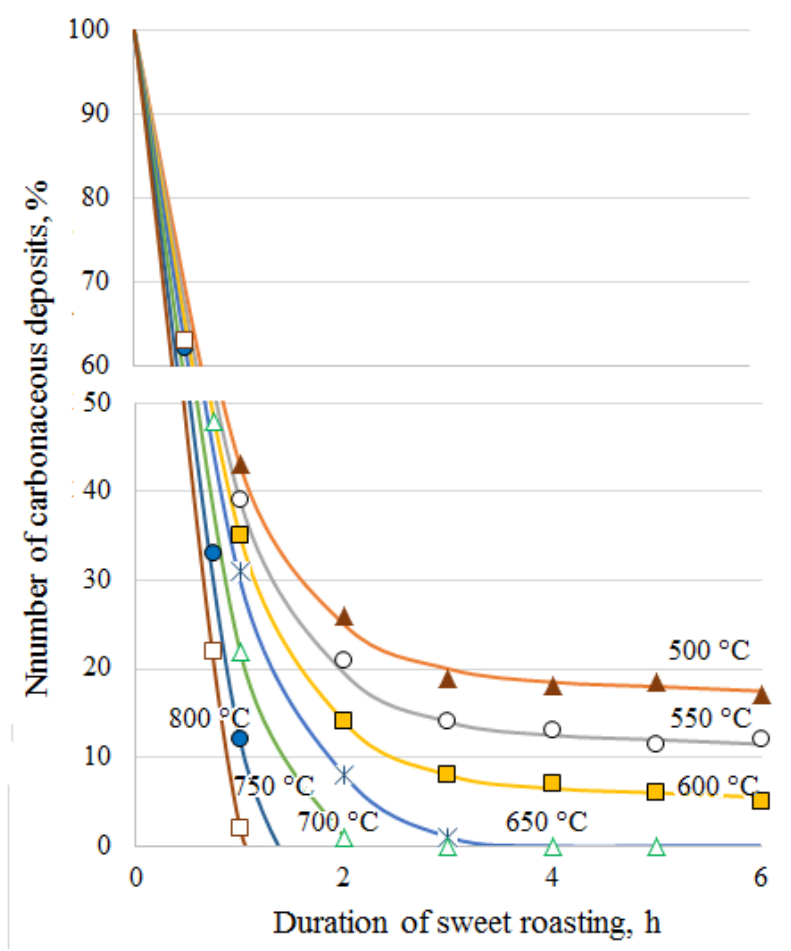


Fig. 2. Residual carbonaceous deposits content on the surface of the catalyst when roasting in the air environment

Approximation of the obtained experimental data by polynoms of the fifth order, and the subsequent mathematical processing of these polynoms allowed to receive the chart illustrating the removal rate of organic deposits depending on the temperature and the time of roasting which is presented in fig. 3 .

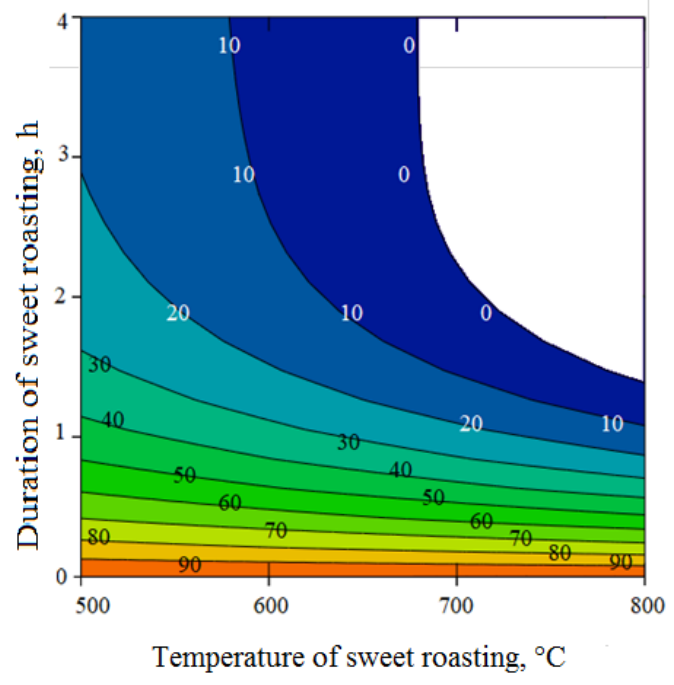

Fig. 3. Influence of the temperature and sweet roasting duration in the air environment on the extent of carbonaceous deposits removal from the surface of the catalyst (Figures at curves are quantity of carbonaceous deposits, \%)

The experimental data obtained allow to admit that at temperature of $800{ }^{\circ} \mathrm{C}$ the complete removal of carbonaceous deposits from the surface of dead catalyst requires not less than 90 minutes, in case the temperature decreases to $700^{\circ} \mathrm{C}$ it will take 2 hours to achieve the same effect. Further temperature decrease leads to roasting time increasing till four hours and more.

When choosing temperature of sweet roasting it is necessary to consider features of structural changes in the alumina carrier: elevated temperatures and their exposure time lead to the increase in a - Al2O3 percent. In is not advisable for the subsequent hydrometallurgical processing. Thus, according to data [14], a newly formed $\gamma$-Al2O3 has solubility degree in an alkaline solution fluctuating from 50 to $65 \%$, and roasted at $70{ }^{\circ} \mathrm{C}$ alumina has chemical activity at the level of 12 $15 \%$.

When roasting catalysts in the air environment it is necessary to consider the most effective exposure time of isothermal holding at $700{ }^{\circ} \mathrm{C}-2$ hours. As we have mentioned above, higher temperature leads to structural changes in the alumina carrier, and the decrease in temperature leads to sharp increase of process time.

It is possible to accelerate the oxidation process of organic deposits by means of increasing the concentration of oxidizer - oxygen in the blown air. Empirical data of annealing organic deposits from the surface of dead catalysts in the atmosphere enriched with oxygen till $30-35 \%$ are presented in the following table.

Table

The number of the remained carbonaceous deposits, $\%$ on the surfaces of the catalyst when annealing in the environment enriched with oxygen 


\begin{tabular}{|c|c|c|c|c|c|c|}
\hline \multirow{2}{*}{$\begin{array}{l}\text { Annealing time, } \\
{[\mathrm{h}]}\end{array}$} & \multicolumn{7}{|c|}{ Annealing temperature $\left[{ }^{\circ} \mathrm{C}\right]$} \\
\cline { 2 - 7 } & 500 & 550 & 600 & 650 & 700 & 750 \\
\hline 1 & 32,6 & 13,4 & 14,2 & 4,6 & 0,5 & 0 \\
\hline 2 & 17,3 & 14,1 & 2,8 & 0,4 & 0 & \\
\hline
\end{tabular}

The process of annealing was carried out at variation of temperature from 500 to $750{ }^{\circ} \mathrm{C}$, isothermal holding was 1 and 2 hours, oxygen was supplied from a cylinder at the rate of $21 / \mathrm{min}$.

Additional supply of oxygen allowed to achieve good surface treatment of the catalyst for further processing, i.e. the complete removal of organic deposits at temperature of $650{ }^{\circ} \mathrm{C}$ within two hours, and at temperature of $700{ }^{\circ} \mathrm{C}$ within one hour. The appearance of the catalyst after annealing at temperature of $700{ }^{\circ} \mathrm{C}$ is presented in fig. 4.

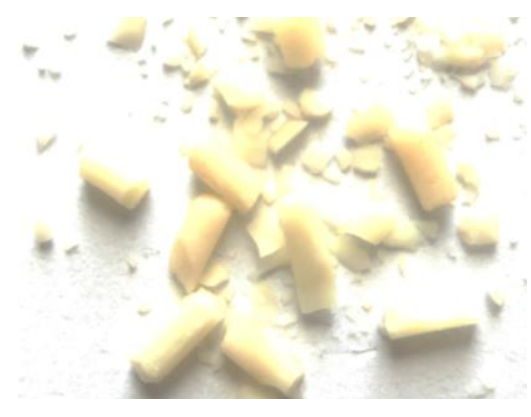

Fig.4. Appearance and inner part of the reforming catalyst after annealing at temperature of $700{ }^{\circ} \mathrm{C}$.

The enterprises which are engaged in processing of the dead catalysts of petroleum chemistry containing precious metals create their own regulations on industrial engineering of catalysts for metallurgical treatment. These regulations have only one similar feature: the residual of organic components (residues of oil products, coke) has to be less than $0.5 \%$. It assumes carrying out the process of roasting at high temperatures and at rather long duration of process.

The method we offered is cost effective; it gives a great opportunity to receive the high-quality product suitable for processing quickly enough.

\section{Conclusions}

The choice of optimal terms of the engineering process of reforming dead catalysts for the extraction of valuable components depends on the subsequent technological processing. Using hydrometallurgical technology of the regeneration of platinum metals (this technology assumes a base dissolving in alkali or acids) it is preferable to carry out process in the environment enriched by oxygen till 30-35 \% that will allow to conduct the engineering process at $650{ }^{\circ} \mathrm{C}$ with holding at the specified temperature within 2 hours and doesn't lead to the significant change in phase structure of the alumina carrier.

If we talk about pyrometallurgical method, for example, rhenium refining at the elevated temperature, then it is economically more expedient to carry out sweet roasting at temperature of $800^{\circ} \mathrm{C}$ within one hour.

\section{References}

[1] Belyy A.S. The current state, prospects of development of process and reforming catalysts of petrol fractions of oil/ A.S. Belyy //the Catalysis in the industry. - 2014. - No. 5. - Page 23-28.

[2] Akhmetov S.A. Technology and equipment for processes of gas and petroleum refining / S.A. Akhmetov, T.P. Serikov, I.R. Kuzeev, M.I. Bayazitov//SPb.: Subsoil. -2006. - 868 pages. 
[3] Kuznetsov P.N. Research of physical and chemical properties of partly spent platinumrhenium reforming catalyst / Kuznetsov P.N. [etc.]//Joutnal of Siberian Federal University. Series: Technique and technologies. - 2014. - T.7. - No. 8. - Page 919-928.

[4] Kuznetsov P. N. Physical and chemical properties of the reforming dead platinum-rhenium catalyst at Achinsk refinery / P.N. Kuznetsov [etc.]//Petroleum Chemistry. - 2013. - T. 53. - No. 6. - Page 436-441.

[5] Haidamaka S. N. About a possibility of supercritical fluid regeneration of industrial Pt-Re/ $\gamma$ $\mathrm{A} 12 \mathrm{O} 3$ reforming catalyst in mixes of the O3/CO2 / Haidamaka S. N. [etc.]//the Catalysis in the industry. - 2013. - No. 3. - Page 27-33.

[6] Kenzhaliyev B.K. Extraction of Pt and Pd from dead catalysts by an electrochemical method / B.K. Kenzhaliyev, T.A. Hodareva, etc.//European Researcher, 2014. - Vol. (70). - No. 3-1. - River $442-449$.

[7] Zorina C.B. New technology of a reactivation of catalysts of hydrotreating of solar oil / S.V. Zo-rina//Sibirskaya Neft Online magazine. - 2016. - No. 9/136. - Page 50-53. URL: http://www.gazpromneft.ru/press-center/sibneft-online/archive/2016-november/1115350/

[8] Masagutov R.M. Regeneration of catalysts in oil processing and petroleum chemistry: monograph / R.M. Masagutov, B.F. Morozov, B.I. Kutepov. - M, Chemistry, 1987. - 141 pages.

[9] Khan M.A. Enhanced decoking of a coked zeolite c atalyst using a glow discharge in $\mathrm{Ar}-\mathrm{O} 2$ gas mixture / M.A. Khan, A.A. Al-Jalal / Appl. Catal. A-Gen. - 2004. - vol. 272. - P. 141-149.

[10] Guryev Y. V. Characterization of metal segregation in Pt-Re/Al2O3 reforming catalysts / Y. V. Guryev [et al.] // Appl. Catal. A-Gen. - 2007. - vol. 329. - P. 16-21.

[11] Pieck C.L. Differences in coke burning-off from Pt-Sn/Al2O3 catalyst with oxygen or ozone / C.L. Pieck [et al.] // Appl. Catal. A-Gen. - 2005. - vol. 278. - P. 173-180.

[12] Gumerov F.M. Sub - and supercritical fluids in processing of polymers / F.M. Gumerov, A.N. Sabirzyanov, G.I. Gumerova. - Prod. "FAN", 2000. - 328 pages.

[13] Sagdeev A. A. Apparatus for the research of extraction processes with use of solvents in a supercritical state / A.A. Sagdeev [etc.]//Patent No. 133012. Russian Federation 2013117145/05 ed. 10.10.2013. Bulletin No. 28. p. -5 .

[14] Grigoriev M.V.,Kulkov S.N. Fluid content, structure and a specific surface area of powder systems on the basis of corundum of various dispersion//the Journal of Siberian Federal University: Technique and technologies. - 2009. - No. 3. - Page 294-300. - P. 5-7. 